\title{
Activation of endogenous opioid gene expression in human keratinocytes and fibroblasts by pulsed radiofrequency energy fields
}

This article was published in the following Dove Press journal: Journal of Pain Research

18 September 2012

Number of times this article has been viewed

\author{
John Moffett' \\ Linley M Fray' \\ Nicole J Kubat ${ }^{2}$ \\ 'Life Science Department, \\ ${ }^{2}$ Independent Consultant, \\ Regenesis Biomedical Inc, \\ Scottsdale, AZ, USA
}

Correspondence: John Moffett 530I N Pima Road Scottsdale, AZ 85250-3773, USA

$\mathrm{Tel}+\mathrm{I} 4809704970$

Fax + I 8668578792

Email moffett@regenesisbio.com
Background: Pulsed radiofrequency energy (PRFE) fields are being used increasingly for the treatment of pain arising from dermal trauma. However, despite their increased use, little is known about the biological and molecular mechanism(s) responsible for PRFE-mediated analgesia. In general, current therapeutics used for analgesia target either endogenous factors involved in inflammation, or act on endogenous opioid pathways.

Methods and Results: Using cultured human dermal fibroblasts (HDF) and human epidermal keratinocytes (HEK), we investigated the effect of PRFE treatment on factors, which are involved in modulating peripheral analgesia in vivo. We found that PRFE treatment did not inhibit cyclooxygenase enzyme activity, but instead had a positive effect on levels of endogenous opioid precursor mRNA (proenkephalin, pro-opiomelanocortin, prodynorphin) and corresponding opioid peptide. In HEK cells, increases in opioid mRNA were dependent, at least in part, on endothelin-1. In HDF cells, additional pathways also appear to be involved. PRFE treatment was also followed by changes in endogenous expression of several cytokines, including increased levels of interleukin-10 mRNA and decreased levels of interleukin-1 $\beta$ mRNA in both cell types.

Conclusion: These findings provide a new insight into the molecular mechanism underlying PRFE-mediated analgesia reported in the clinical setting.

Keywords: peripheral analgesia, endogenous opioids, endothelin-1, endothelin receptor A, endothelin receptor B, pulsed radiofrequency energy field, cyclooxygenase

\section{Introduction}

Understanding the cellular and molecular basis of nociception is a challenge that has important implications for pain management and the development of new analgesics. Nociception plays a vital role in the survival of the organism, serving to transmit warning signals of impending harm. ${ }^{1-3}$ However, beyond this function, the experience of prolonged nociceptive and inflammatory pain, such as following surgery or other trauma, requires effective management, both to provide comfort for the patient and to reduce the possible risk of development of chronic pain. ${ }^{4,5}$

As somatosensory neurons of the peripheral nervous system, nociceptors innervate the periphery and function to detect noxious mechanical, temperature, and chemical stimuli. Via communication with the central nervous system, nociceptor activity functions to evoke pain sensation at the site of injury, and nociceptor sensitivity (ie, firing threshold) to stimuli at the site can be modulated by soluble factors released by local nonneuronal cells, eg, keratinocytes, fibroblasts, and infiltrating immune cells. ${ }^{1-3}$ Certain factors, such as nerve growth factor alpha, prostaglandins, eg, prostaglandin $\mathrm{E}_{2}$, and 
proinflammatory cytokines, eg, tumor necrosis factor-alpha (TNF- $\alpha$ ) and interleukin (IL)- $1 \beta$, can promote nociceptor hypersensitivity, ${ }^{1,3,6}$ whereas other factors, such as anti-inflammatory cytokines, eg, IL-10 and IL-4, and endogenous opioids, can have the opposite effect on nociceptor firing, thereby acting as analgesics. ${ }^{3,6}$

New analgesic pharmaceuticals are actively being pursued. Many of these drugs fall into the class of nonsteroidal antiinflammatory drugs, which primarily target cyclooxygenases (ie, COX-1 and COX-2), ${ }^{7}$ which are enzymes involved in prostaglandin synthesis. Opioids are still the most widely used drugs for treatment of severe and pathological pain. However, important side effects associated with these pharmacological options continue to be a major drawback. ${ }^{8,9}$ This has spurred an interest in multimodal therapy as a way of facilitating decreased intake of any one type of analgesic. ${ }^{10}$ To optimize such an approach, novel adjunctive therapy options with limited side effects are needed. Recently, biophysical treatment modalities have been shown to be useful as an adjunctive analgesic therapy option. One such modality, pulsed radiofrequency energy (PRFE), is an adjunctive therapy which involves local noninvasive delivery of PRFE (27.12 $\mathrm{mHz}$ carrier frequency) to superficial soft tissue, a treatment which has been reported to provide analgesic benefit in patients following surgery or other soft tissue trauma, with few reports of side effects. ${ }^{11}$ Three recent, randomized, double-blind clinical trials that used PRFE field treatment for pain in post-surgical patients found significantly reduced levels of reported pain as well as analgesic consumption in patients treated with PRFE relative to control patients treated with a sham device. ${ }^{12-14}$ A meta-analysis of studies assessing the clinical efficacy of PRFE also found that a significant proportion of studies that assessed PRFE use for pain reported a beneficial outcome (11 positive studies). ${ }^{15}$

While clinical results are promising, little is known regarding the underlying mechanism of action of PRFEmediated analgesia. In previous studies using cultured human keratinocytes and fibroblasts, PRFE treatment was found to mediate rapid and widespread upregulation of endogenous transcripts of multiple factors that, in vivo, are involved in cutaneous wound healing. ${ }^{16,17}$

In the current study, we used the same system to examine whether PRFE treatment has an effect on the expression of factors known to modulate nociception, including endogenous targets of other analgesic therapeutics. The results suggest that, unlike nonsteroidal anti-inflammatory drugs, PRFE does not inhibit cyclooxygenase enzymes, but instead has a positive effect on the expression of endogenous opioids as well as their secretion, possibly via an endothelin pathwaybased mechanism.

\section{Materials and methods Materials}

Culture medium (Minimal Essential Medium) was purchased from Cell Applications Inc (San Diego, CA) and from Mediatech Inc (Herndon, VA) for general culture of human dermal fibroblasts (HDF). Fetal calf serum, penicillinstreptomycin, trypsin, $1 \times$ phosphate-buffered solution, sodium pyruvate, and nonessential amino acids were purchased from Hyclone (Logan, UT). Reagents for reverse transcription polymerase chain reaction (RT-PCR) were from Life Technologies (Carlsbad, CA). Oligonucleotide primers for PCR were purchased/synthesized by Real Time Primers (Elkins Park, PA). General chemicals were purchased from Sigma-Aldrich (St Louis, MO) or VWR International (Radnor, PA). Endothelin A and B receptor antagonists were purchased from American Peptide (Sunnyvale, CA).

\section{Cell culture}

HDF cells were purchased from Cell Applications Inc (San Diego, CA). Routine culture was performed as recommended by the manufacturer in a $5 \% \mathrm{CO}_{2}$ humidified incubator at $37^{\circ} \mathrm{C} .{ }^{18}$ For the experiments, cells were cultured on $10 \mathrm{~cm}$ plates at a density of $1.14 \times 10^{4} \mathrm{cells} / \mathrm{cm}^{2}$ in Minimum Essential Medium supplemented with $1 \mathrm{mM}$ sodium pyruvate, $1 \mathrm{mM}$ nonessential amino acids, 100 units penicillin, $100 \mu \mathrm{g}$ streptomycin, and 5\% fetal calf serum. Cells were used for experimentation after 16 hours in a humidified incubator at $37^{\circ} \mathrm{C}$ with $5 \% \mathrm{CO}_{2}$. Cells were used for experimentation from passage 5 to 10. Human epidermal keratinocytes (HEK) cells were purchased from Cell Applications Inc. Routine culture was performed as recommended by the manufacturer in a $5 \% \mathrm{CO}_{2}$ humidified incubator at $37^{\circ} \mathrm{C}$. For experiments, keratinocytes were cultured on $10 \mathrm{~cm}$ plates at a density of $0.75 \times 10^{4}$ cells $/ \mathrm{cm}^{2}$ in keratinocyte growth medium supplied by the manufacturer. HEK were used for experimentation after 16 hours in a humidified incubator at $37^{\circ} \mathrm{C}$ with $5 \% \mathrm{CO}_{2}$. HEK were used for experimentation from passage 5 to 7 .

\section{PRFE conditions and treatment}

Treatment was performed by exposing cells to the PRFE field of a Provant ${ }^{\circledR}$ device from Regenesis Biomedical Inc (Scottsdale, AZ). This device emits a $27.12 \mathrm{mHz}$ radiofrequency signal transmitted from a flat spiral antenna with a radius of $7.5 \mathrm{~cm}$ made up of six turns at a width of $0.70 \mathrm{~cm}$ spaced with a separation of $0.3 \mathrm{~cm}$. The signal is delivered in 
$42 \mu \mathrm{sec}$ pulses with a period of $1 \mathrm{kHz}$. This corresponds to energy parameters of $591 \mathrm{~V} / \mathrm{M}$ and $6.7 \mathrm{~A} / \mathrm{M}$ in electrical and magnetic fields, respectively, when measured $5 \mathrm{~cm}$ from the surface of the radiating antenna. Cells were placed at a distance of $5 \mathrm{~cm}$ from the source during treatment. Treatment was performed at room temperature for 30 minutes after which the cells were returned to the incubator. Cells were harvested for protein or total RNA at the times indicated in the figures. Treatment under these conditions is referred to herein as "PRFE".

\section{RNA isolation and real-time quantitative RT-PCR}

Cells were treated with PRFE for 30 minutes, and total RNA was isolated using an RNeasy Mini kit (Qiagen, Valencia, CA) isolation kit. Total RNA $1 \mu \mathrm{g}$ was reverse-transcribed using a high-capacity RNA to cDNA master mix (Life Technologies) following the manufacturer's instructions. PCR was performed using the following reaction times and temperatures: denaturation for 15 seconds at $94^{\circ} \mathrm{C}$, annealing for 30 seconds at $55^{\circ} \mathrm{C}$, and elongation for 30 seconds at $72^{\circ} \mathrm{C}$ in $20 \mu \mathrm{L}$ reaction volumes, and run out to 45 cycles using a Rotor-Gene device (Qiagen). Primer sequences are shown in Table 1 and were purchased from RealTimePrimers. Quantitation and analysis of relative gene expression was performed using the $2^{-\Delta \Delta C T}$ method described by Livak and Schmittgen. ${ }^{19}$ Glyceraldehyde phosphate dehydrogenase was used to normalize product expression between different RNA samples and treatments. RNA was isolated from at least four independent experiments and PCR was performed in triplicate. Products were electrophoresed on $2 \%$ agarose gel and stained with ethidium bromide to determine the fidelity of the PCR reaction. The relationship between the concentration of input RNA and amount of PCR product was linear for each PCR product.

\section{Protein content analysis of opioids and endothelin- I}

We used an enzyme-linked immunosorbent assay to measure cytokine and opioid levels in cell supernatants after treatment with PRFE. For cytokine and opioid measurement, cells were plated at $5.0 \times 10^{4}$ per well in 24-well dishes (BD Biosciences, Franklin Lakes, NJ). The cells were incubated for 24 hours, after which $400 \mu \mathrm{L}$ of fresh medium was added. Cells were then treated with PRFE, and the media and cell lysate were harvested at the times indicated in the figures and then analyzed for opioid, substance P (Phoenix Pharmaceuticals, Burlingame, CA), or endothelin-1 expression. B-endorphin, substance P, dynorphin, and enkephalin (Wuhan EIAab Science Co, Ltd, Wuhan, China) were analyzed by
Table I Primer Sequences used for qRT-PCR.

\begin{tabular}{|c|c|}
\hline Oligo Name & Primer sequence ( $5^{\prime}$ to $\left.3^{\prime}\right)$ \\
\hline \multirow[t]{2}{*}{ GADPH } & GAGTCAACGGTTTGGTCGT \\
\hline & TTGATTTTGGAGGGATCTCG \\
\hline \multirow[t]{2}{*}{ PENK } & AGCTGTCCCAACCCAGAGCTT \\
\hline & ССТССТСTGСАTССTTСTTC \\
\hline \multirow[t]{2}{*}{ POMC } & ССССTACAGGATGGAGCACT \\
\hline & CGTTCTTGATGATGGCGTTT \\
\hline \multirow[t]{2}{*}{ PDYN } & AAGCTCTCTGGGTCATTCCT \\
\hline & TCCСTCATCAGCTCAGACTC \\
\hline \multirow[t]{2}{*}{ ET-I } & TCCCGTTCAGAAGACAGCTT \\
\hline & CAGAGGGCAAAGACAAGGAC \\
\hline \multirow[t]{2}{*}{$\mathrm{ET}_{\mathrm{A}}$ RECEPTOR } & TCGAGAAAGTGGCAAAAACAG \\
\hline & TGAATTCATGGTTGCCAAGT \\
\hline \multirow[t]{2}{*}{$\mathrm{ET}_{\mathrm{B}}$ RECEPTOR } & TCCCGTTCAGAAGACAGCTT \\
\hline & CAGAGGGCAAAGACAAGGAC \\
\hline \multirow[t]{2}{*}{ COX-I } & TTCGGTGTCCAGTTCCAATA \\
\hline & ACCCCATAGTCCACCAACAT \\
\hline \multirow[t]{2}{*}{ COX-2 } & TCTGAAACCCACTCCAAACA \\
\hline & AAGGCTTCCCAGCTTTTGTA \\
\hline \multirow[t]{2}{*}{ PTGES } & GTGGCTATACCTGGGGACTT \\
\hline & CTTGAAATGGTTCCCATCAG \\
\hline \multirow[t]{2}{*}{ PTGDS } & GGCAGGTATGTCACCGTTCT \\
\hline & TTCATCCTGGCCTTTTCATC \\
\hline \multirow[t]{2}{*}{ IL-I0 } & AAGCCTGACCACGCTTTCTA \\
\hline & ATGAAGTGGTTGGGGAATGA \\
\hline \multirow[t]{2}{*}{ IL-I $\beta$} & TTCGACACATGGGATAACGA \\
\hline & TCTTTCAACACGCAGGACAG \\
\hline \multirow[t]{2}{*}{ IL-6 } & ATGCAATAACCACCСCTGAC \\
\hline & GAGGGTGCCCATGCTACATTT \\
\hline \multirow[t]{2}{*}{ NGF } & ATACAGGCGCGGAACCACACTC \\
\hline & TGCTCCTGTGAGTCCTGTTG \\
\hline \multirow[t]{2}{*}{ TNF- $\alpha$} & TCCTTCAGACCACCCTCAACC \\
\hline & AGGCCCCAGTTTGAATTCTT \\
\hline
\end{tabular}

enzyme-linked immunosorbent assay. Two independent experiments were performed in triplicate for each opioid. Both assays were performed using the manufacturers' protocols. Assays were based on competition with a known concentration of a specific opioid or substance P standard. Endothelin-1 concentration was determined by a standard curve with known concentrations.

\section{Analysis of cyclooxygenase activity}

Cells were inoculated at a density of $5 \times 10^{5}$ cells per plate and grown for 24 hours. PRFE treatment was performed using standard conditions and cells were harvested at the indicated times. Cell lysates were made up in $0.1 \mathrm{M}$ Tris- $\mathrm{HCl}(\mathrm{pH} 7.4)$ containing aprotinin $3.3 \mu \mathrm{g} / \mathrm{mL}$, leupeptin $10 \mu \mathrm{g} / \mathrm{mL}$, and pepstatin $4 \mu \mathrm{g} / \mathrm{mL}$ (Sigma-Aldrich). Cells were lysed by freeze thawing three times followed by passage through a 26-gauge needle. The protein concentration was then determined, and cyclooxygenase activity was assayed using a fluorescent activity assay kit (Cayman Chemicals, Ann Arbor, MI) by deter- 
mining the conversion of 10-acetyl-3, 7-dihydroxyphenoxazine to resorufin by the peroxidase component of cyclooxygenase. Resorufin fluorescence is then analyzed with an excitation wavelength of 530-540 $\mathrm{nm}$ and an emission wavelength of 585-595 nm using a BioTek FL $\times 800$ fluorescent plate reader. Assays were performed with at least three separate protein isolations, and enzyme activity was run in triplicate.

\section{Statistical analysis}

Enzyme-linked immunosorbent assay and RT-PCR data were analyzed using one-way analysis of variance. If the equal variance test failed for one-way analysis of variance, Dunn's method for multiple comparisons was used. For all the experiments, reporting $P<0.05$ was considered to be statistically significant. All the data were analyzed using SigmaPlot version 11.0.

\section{Results \\ PRFE treatment of HDF enhances cyclooxygenase mRNA expression and activity, with no effect on HEK}

Prostaglandins are an important group of compounds that are closely involved in pain via the inflammation process, and inhibition of their synthesis is the target for nonsteroidal anti-inflammatory drugs. There are many prostaglandins synthesized, all of which proceed through the rate-limiting enzyme, cyclooxygenase. We treated HDF and HEK cells in culture with PRFE fields to determine the effect on $C O X$ gene expression. HDF cells treated with PRFE showed a 1.51-2.3 increase in inducible COX-2 gene expression and no increases in mRNA expression of COX-1 (Figure 1B and C). In HEK cells, no significant changes were observed in levels of either $C O X-1$ or $C O X-2$ gene expression (Figure 1A or C). Because PRFE field treatment had an increasing or no effect on cells in culture (HDF and HEK, respectively), expression of enzymes subsequently involved in the synthesis of prostaglandins was assayed. Prostaglandins $\mathrm{D}$ and $\mathrm{E}_{2}$ are important components in the process of inflammation. Prostaglandin $\mathrm{E}_{2}$ has been shown to be proinflammatory and involved in eliciting pain in the peripheral and central nervous systems. Prostaglandin D plays an important role in the resolution of inflammation. Using RT-PCR, we determined the effects of PRFE on mRNA expression levels of these enzymes. We found increases in prostaglandin $\mathrm{E}$ synthase levels in HDF cells (2.0-fold) with no changes in prostaglandin D synthase levels. In HEK, we found no significant changes in prostaglandin $\mathrm{E}$ synthase expression levels and low mRNA levels of prostaglandin D synthase. We next determined the effects of PRFE on protein activity to address any post-translation modification that PRFE may induce in cyclooxygenase activity. As shown in Figure 2A and $\mathrm{B}$, total cyclooxygenase activity changes mimic those found in changes in mRNA levels of HDF and HEK.

\section{PRFE field treatment of HEK and HDF stimulates endogenous opioid expression}

Peripheral expression of endogenous opioids is becoming recognized as an increasingly important analgesic mechanism in pain pathways due to tissue damage and injury, especially in skin, muscles, and viscera. We determined the effect of PRFE treatment on pro-opiomelanocortin $(P O M C)$, pro-enkephalin $(P E N K)$, and prodynorphin $(P D Y N)$ gene expression in HEK and HDF. These endogenous opioids have been shown to be involved in antinociceptive pathways in peripheral tissue. In particular, immune cells and keratinocytes have been shown to express endogenous opioid peptides, which are thought to elicit an analgesic effect during trauma to skin. Cells treated with PRFE showed an increase in endogenous opioid gene expression with a maximum at 2 hours following treatment. Both HEK and HDF showed increases of all three opioid mRNA levels as shown in Figure 3A. This suggests that, at least in part, the analgesic effects of PRFE fields may be through increased expression of pro-opioid mRNA.

We next looked at the levels of $\beta$-endorphin, enkephalin, and dynorphin peptides after PRFE treatment. Both enkephalin and dynorphin peptides are increased in HEK and HDF (Figure 3B and C). We could not detect B-endorphin peptide, probably due to the sensitivity of the assay. These results suggest a biological mechanism whereby treatment of injured tissue with PRFE fields decreases pain associated with the trauma in a localized manner.

\section{PRFE fields activate cytokine expression involved in opioid expression and release}

We have previously shown that PRFE field treatment of HEK and HDF increases many cytokines and other proteins involved in the inflammation phase of wound healing. Several cytokines have been implicated in modulating pain after dermal injury. Proinflammatory cytokines such as IL- $1 \beta$ have been shown to be particularly important in the release of endogenous opioids from leukocytes. We determined the effects of PRFE field treatment on several cytokines and neurokine factors, which have been shown to be involved in pain produced by neuroinflammation and resolution of the inflammation process (Figure 4). The proinflammatory cytokine IL- $1 \beta$ has been implicated 

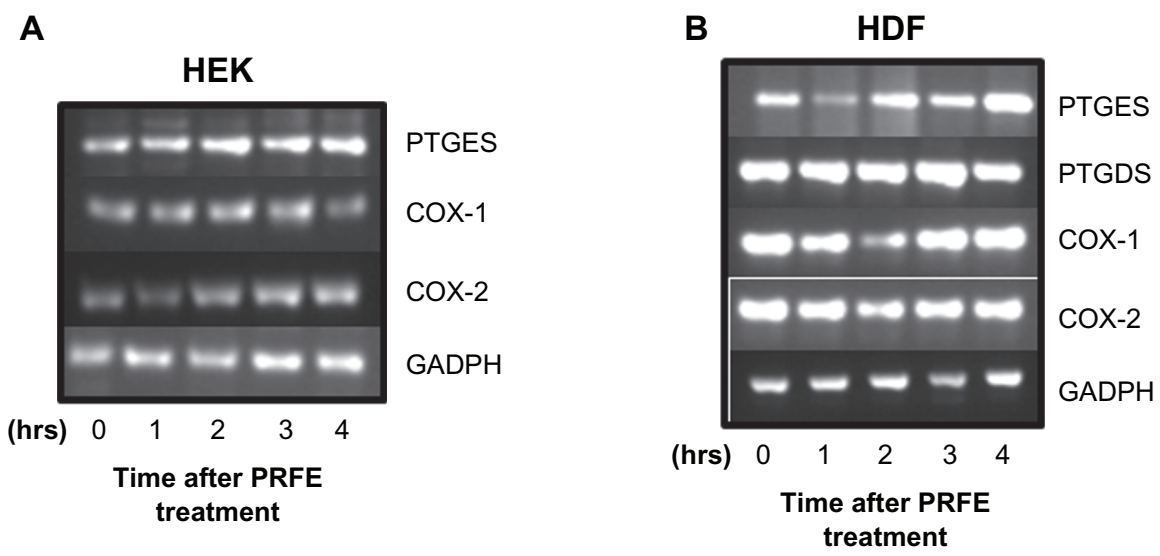

C

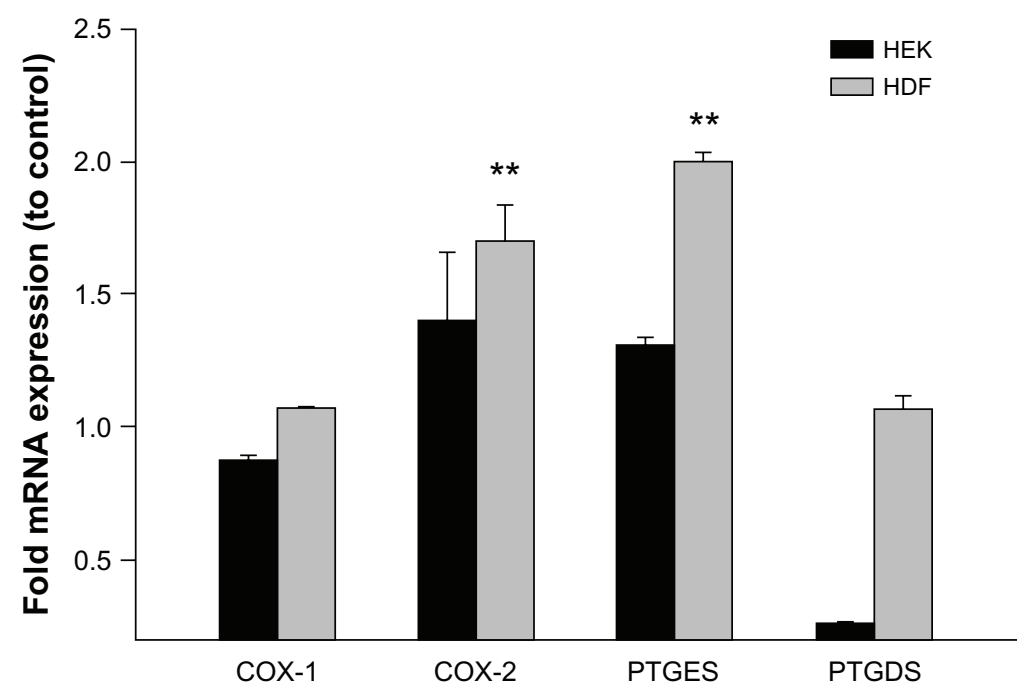

Figure I Effect of PRFE treatment on COX mRNA and prostaglandin D and E synthase expression in HEK and HDF in culture. (A and B) We evaluated the effect of PRFE treatment on levels of mRNA expression after 30 minutes of treatment with PRFE using standard conditions. Cells were harvested 4 hours following initiation of PRFE treatment and the RT-PCR products were analyzed by electrophoresis through $2 \%$ agarose gel. (C) Quantitative RT-PCR was used to determine the effect of PRFE on message levels for the various genes involved in prostaglandin synthesis (**P $<0.05$ for control versus PRFE treatment) in HDF.

Abbreviations: COX, cyclooxygenase; GADPH, glyceraldehyde 3-phosphate dehydrogenase; HDF, human dermal fibroblasts; HEK, human epidermal keratinocytes; RT-PCR, reverse transcription polymerase chain reaction; PRFE, pulsed radiofrequency energy; PTGDS, prostaglandin D synthase; PTGES, prostaglandin E synthase.

in stimulating release of endogenous opioids from immune cells. In our studies, IL-1 $\beta$ was decreased in both cell types. Compared with control cells, PRFE-treated HEK and HDF expressed higher levels of IL-5, IL-6, and IL-10 (Figure 4). Nerve growth factor alpha mRNA levels were increased in PRFE-treated fibroblasts, while a lower level of nerve growth factor alpha mRNA relative to control was observed following treatment of keratinocytes. In addition, PRFE-treated HEK also had lower levels of TNF- $\alpha$ mRNA compared with the control. Substance P expression was not found in either of the cell types (data not shown). Previous results of a microarray analysis found upregulation of several cytokine mRNAs following PRFE treatment; ${ }^{16}$ however, as here, these cytokines did not include those commonly implicated in stimulating endogenous opioid release from immune cells, eg, IL- $1 \beta$ and TNF- $\alpha$. Combined, these results indicate that PRFE fields do not act through traditional cytokine mechanisms, which stimulate endogenous opioid release from immune system cells via factors such as IL-1 $\beta$.

\section{Increase in opioid expression is mediated by an endothelin-I pathway in keratinocytes}

Endothelin-1 is associated with the pathogenesis of ischemia and cancer, and is a potent vasoconstrictor often associated with peripheral pain. Its pain response is associated with its binding to the endothelin $\mathrm{A}$ receptor $\left(\mathrm{ET}_{\mathrm{A}}\right)$ on nociceptors. In contrast, binding of ET-1 to endothelin $\mathrm{B}\left(\mathrm{ET}_{\mathrm{B}}\right)$ receptors has been shown to produce localized analgesia by inducing expression of endogenous opioids in HEK. PRFE treatment of HEK increased expression of the $\mathrm{ET}_{\mathrm{B}}$ receptor as well as mRNAs for PENK, PDYN, and POMC. $\mathrm{ET}_{\mathrm{A}}$ and endothelin-1 showed no significant 

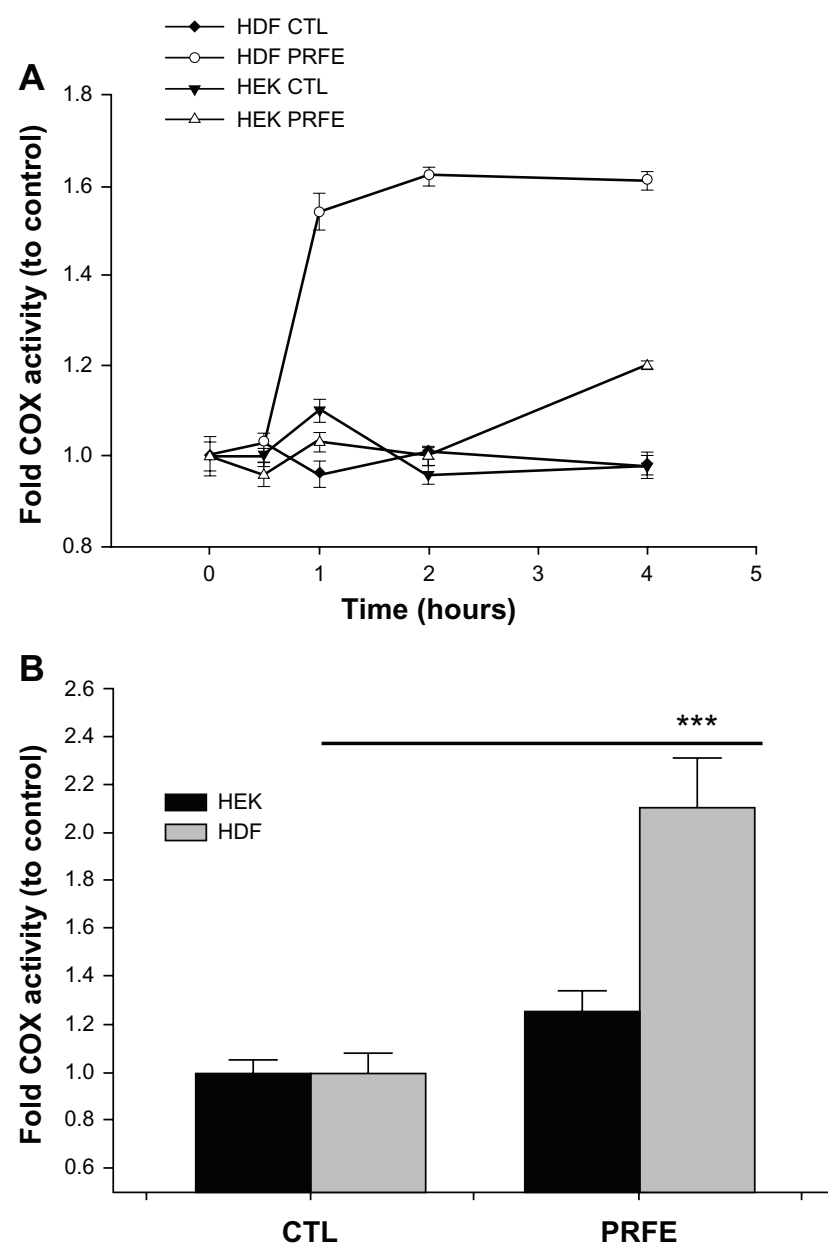

Figure 2 Effect of PRFE fields on COX enzyme activity in HEK and HDF. Total COX enzyme activity was determined after PRFE field treatment. (A) COX was evaluated after PRFE treatment at the indicated times. Data shown are from at least two independent experiments performed in triplicate. (B) Effect at 4 hours following PRFE treatment ( $n=6$, ${ }^{* * * P}<0.01$ for HDF).

Note: No statistically significant differences in COX enzyme activity were found between HEK and untreated controls.

Abbreviations: CTL, control; COX, cyclooxygenase; HDF, human dermal fibroblasts; HEK, human epidermal keratinocytes; PRFE, pulsed radiofrequency energy.

increases in mRNA levels. In HDF, PRFE treatment showed increases in all three of the pro-opioid mRNAs, with decreasing expression of endothelin-1 mRNA (Figure $5 \mathrm{~A}$ and $\mathrm{B}, P<0.05$ ). $\mathrm{ET}_{\mathrm{A}}$ and $\mathrm{ET}_{\mathrm{B}}$ receptors showed no statistically significant differences in expression after PRFE treatment over controls in HDF. These results suggest that PRFE treatment produces peripheral analgesia by increasing endogenous opioid expression via endothelin-1 binding to its $\mathrm{ET}_{\mathrm{B}}$ receptor in $\mathrm{HEK}$, but via multiple pathways in HDF.

\section{$\mathrm{ET}_{\mathrm{A}}$ and $\mathrm{ET}_{\mathrm{B}}$ receptor antagonists have different mechanisms of endogenous opioid induction in HEK and HDF}

Khodorova et $\mathrm{al}^{20,21}$ have shown that increases in endogenous opioid expression via the endothelin-1 pathway are
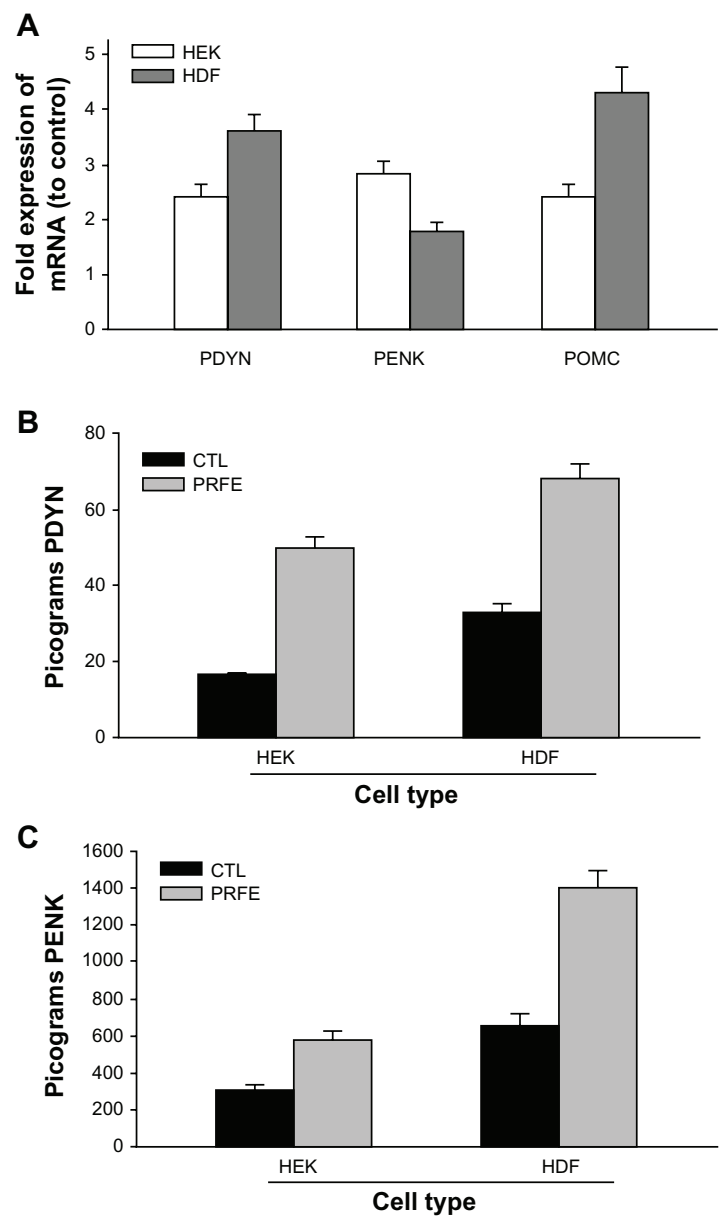

Figure 3 PRFE increases endogenous opioid expression in HEK and HDF at the mRNA and peptide levels. (A) Endogenous opioid expression was determined in HEK and HDF. Cells were treated with PRFE and total RNA was isolated after 2 hours ( $\mathrm{n}=12, P<0.01$ for all opioids, control versus PRFE-treated). (B and $\mathbf{C}$ ) Determination of PDYN and PENK opioid levels at 2 hours following PRFE treatment using enzyme-linked immunosorbent assay (error bars show standard error of the mean, two separate experiments in triplicate, $P<0.05$ ).

Abbreviations: CTL, control; HDF, human dermal fibroblasts; HEK, human epidermal keratinocytes; PRFE, pulsed radiofrequency energy; POMC, proopiomelanocortin; PENK, proenkephalin; PDYN, prodynorphin.

mediated through binding to the $\mathrm{ET}_{\mathrm{B}}$ receptor. We used the inhibitors BQ-123 and BQ-788. BQ-123 is a selective antagonist for $\mathrm{ET}_{\mathrm{A}}$ receptors whereas $\mathrm{BQ}-788$ is a selective antagonist for $\mathrm{ET}_{\mathrm{B}}$ receptors. Cells were treated with either antagonist followed by treatment with PRFE. Levels of endogenous opioid mRNA expression were measured at 2 hours after treatment (Figure 6). Both antagonists inhibited PRFE-induced increases in opioid expression in HEK. In HDF, both BQ-788 and BQ-123 inhibited endogenous PENK and POMC expression, but PYDN expression was unaffected after PRFE field treatment. These results show that increases in opioid expression in HEK are induced at least in part by an endothelin-1-dependent mechanism binding to its receptors, ie, $\mathrm{ET}_{\mathrm{A}}$ and $\mathrm{ET}_{\mathrm{B}}$. In fibroblasts, the role for induction by endothelin-1 is less clear, with endothelin 


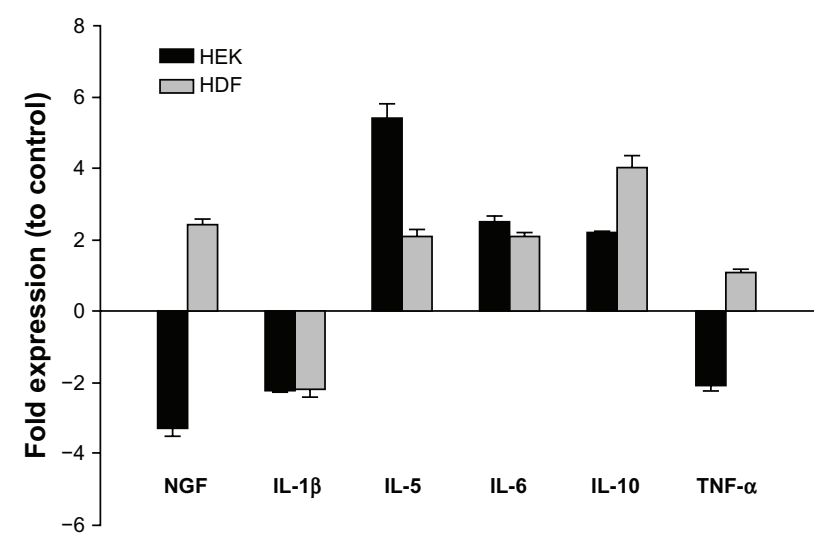

Figure 4 Regulation of cytokines involved in the peripheral pain response. Notes: Cytokine expression was determined using quantitative RT-PCR. HEK or HDF were treated with PRFE using standard conditions. Total RNA was isolated 2 hours following treatment. Levels are expressed as a fold increase or a fold decrease ( $n=6$, error bars show standard error of the mean, differences for control versus PRFE-treated are $P<0.05$ ).

Abbreviations: HDF, human dermal fibroblasts; HEK, human epiderma keratinocytes; IL, interleukin; NGF- $\alpha$, nerve growth factor alpha; TNF- $\alpha$, tumor necrosis factor-alpha; RT-PCR, reverse transcription polymerase chain reaction.

receptor antagonist blockade inhibiting POMC and PENK expression but having no effect on induction of PYDN after treatment with PRFE.

\section{Discussion}

Many analgesic therapies have historical derivations that are still used today, such as opioid-based medications and nonsteroidal anti-inflammatory drugs, which are currently the mainstay of treatment for postoperative pain. Although effective for many types of pain, the data suggest that adverse effects associated with postoperative pain medication are an issue of patient concern. ${ }^{22}$ A survey by Apfelbaum et al found that $23 \%$ of their postoperative patients experienced side effects related to postoperative pain medication, with $72 \%$ of patients surveyed stating that, if given a choice, they would choose a non-narcotic pain medication. ${ }^{22}$ This highlights the need for novel analgesic therapies that are effective with fewer side effects. In our study, we sought to gain insight into the underlying molecular mechanism of a relatively new modality which uses pulsed electromagnetic fields to treat pain due to postoperative or other soft tissue trauma. Unlike exogenous opioid and nonsteroidal anti-inflammatory therapeutics, little is known about the biological mechanism of action of PRFE in mediating analgesia. In injured skin, factors expressed and secreted by non-neuronal cells (ie, resident dermal and epidermal cells, such as fibroblasts and keratinocytes, as well as infiltrating immune cells) in the proximity of nociceptive nerve termini can modulate nociceptor sensitivity, and thus can have an effect on downstream pain sensation, with either a proalgesic or analgesic effect. In the current study, we sought to gain insight into the molecular mechanism of PRFE-mediated analgesia by investigating the effect of PRFE field treatment on the expression of such factors by cultured fibroblasts and keratinocytes following PRFE treatment. This hypothesis was based on the previous finding that PRFE mediates widespread mRNA level increases for diverse endogenous factors in the same in vitro system.

Unlike nonsteroidal anti-inflammatory drugs, which inhibit cyclooxygenase activity, PRFE had a modestly positive effect on cyclooxygenase activity in HDF. It also had a positive effect on mRNA levels of enzymes involved in prostaglandin synthesis (cyclooxygenase-2, prostaglandin E synthase, Figure 1). In contrast, PRFE treatment of these cells led to significant increases in endogenous opioid precursor mRNA (Figure 3A) and secreted opioid peptides (Figure 3B and $\mathrm{C}$ ), an effect that, in most cases, was dependent on endothelin receptors (Figure 6). In addition, PRFE also had an effect on mRNA levels of several cytokines and neurokines (Figure 4). It should be noted that it is not unusual that the two cell types, which in vivo are resident cells from different parts of the skin (keratinocytes derived from the epidermal layer and fibroblasts derived from the dermis), were found to have different gene expression profiles for some of the mRNAs examined here, considering the complexity of individual cell types. For example, in other models, these two cell types have been found to show quantitative differences in levels of mRNAs encoding oxidative stress response proteins ${ }^{23}$ and cytokines. ${ }^{24}$

Although the role of immune cells in antinociception is well accepted, ${ }^{25}$ the precise role of opioid expression by keratinocytes and fibroblasts in peripheral analgesia is not well understood. Khodorova et al have previously shown that $\mathrm{ET}_{\mathrm{B}}$ receptor activation by endothelin-1 stimulates $\beta$-endorphin secretion by keratinocytes, ${ }^{20}$ supporting their finding that $\mathrm{ET}_{\mathrm{B}}$ receptor activation mediates analgesia through a mechanism involving opioid receptors..$^{20}$ In our study, using selective antagonists for endothelin receptors $\left(\mathrm{ET}_{\mathrm{A}}\right.$ and $\left.\mathrm{ET}_{\mathrm{B}}\right)$, we found that the PRFE-mediated increases in PYN, PENK, and POMC mRNA in HEK were blocked by both $\mathrm{ET}_{\mathrm{A}}$ and $\mathrm{ET}_{\mathrm{B}}$ receptor antagonists (Figure 6), suggesting that both types of endothelin receptors play a role in regulating endogenous expression of opioids at either the transcriptional or post-transcriptional level. In HDF, while endothelin receptor antagonists reduced the positive effect of PRFE on levels of PENK and POMC mRNA, both receptor antagonists appeared to enhance the PRFE-mediated 
A

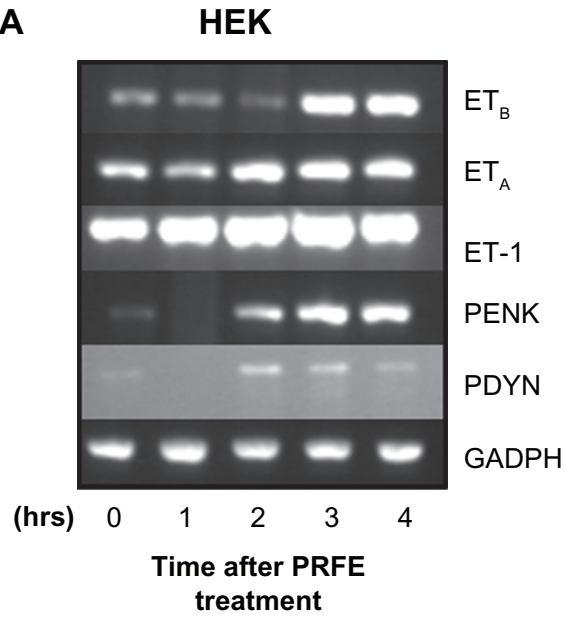

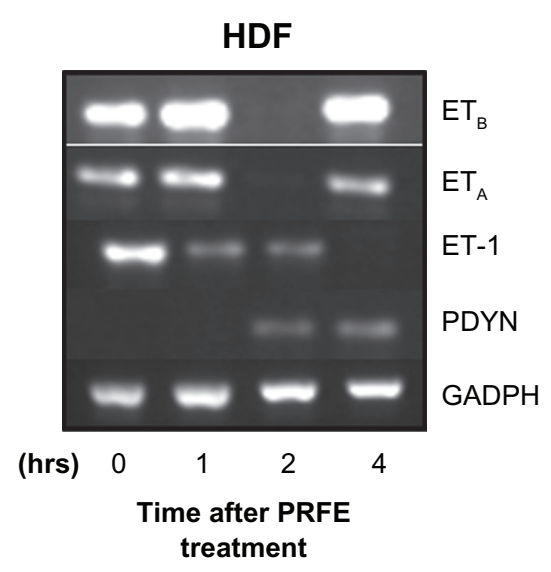

B

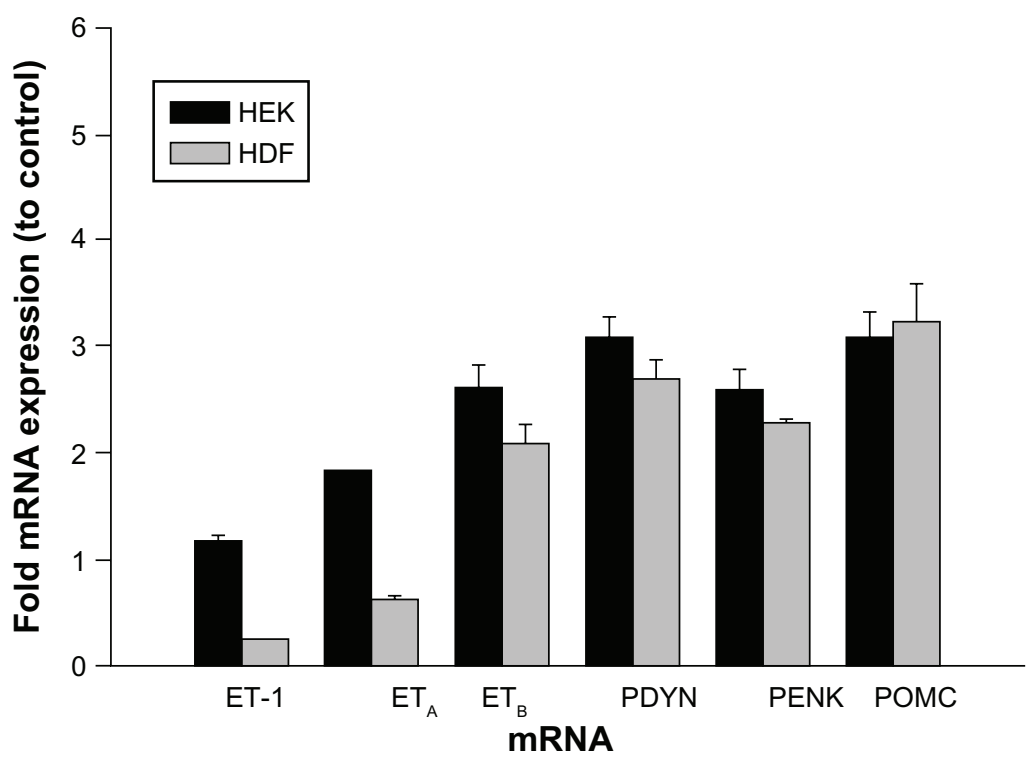

Figure 5 Increased expression of endogenous opioids is regulated by an ET-I/ET ${ }_{B}$ receptor pathway after treatment with PRFE. (A) mRNA expression levels after treatment with PRFE using standard conditions. Cells were harvested after PRFE treatment at the indicated times and RT-PCR products were analyzed by electrophoresis through $2 \%$ agarose gel. (B) Quantitative RT-PCR was used to determine the effect of PRFE on message levels of the endogenous opioids, ET-I and ET .

Notes: Differences between controls and PRFE-treated cells were significant $(P<0.05)$ for all opioid mRNAs in both HEK and HDF. Increases in ET ${ }_{B} m R N A$ were significant $(P<0.05)$ in HEK only.

Abbreviations: ET, endothelin; GADPH, glyceraldehyde 3-phosphate dehydrogenase; HDF, human dermal fibroblasts; HEK, human epidermal keratinocytes; PRFE, pulsed radiofrequency energy; POMC, pro-opiomelanocortin; PENK, proenkephalin; PDYN, prodynorphin; RT-PCR, reverse transcription polymerase chain reaction.

increase in PYDN mRNA levels, suggesting that PRFE can induce endogenous opioid expression through more than one pathway. In both cell types, the PRFE-mediated increase in opioid mRNA occurred concomitantly with an increase in $\mathrm{ET}_{\mathrm{B}}$ receptor mRNA (Figure 6), an effect which was also diminished by endothelin receptor antagonists.

While the effect of PRFE on enzymes that synthesize prostaglandins may seem counter to what one might expect for an analgesic, recent findings by Serhan et al show that prostaglandins $\mathrm{E}_{2}$ and $\mathrm{D}_{2}$, while important for acute inflammation, upon modification (lipid mediator class-switching) could play an important role in the resolution of inflammation and return to homeostasis. ${ }^{26,27}$ Both prostaglandins
$\mathrm{E}_{2}$ and $\mathrm{D}_{2}$ are thought to act as important transcriptional regulators of enzymes involved in the generation of lipoxins and resolvins, ${ }^{8,28}$ which have been shown to play an important role in the resolution of acute inflammation and pain. Future studies to examine what effect PRFE may have on the resolvin and lipoxin pathways are of interest.

Several cytokines and neurokines are also implicated in the direct and indirect modulation of nociception in vivo. For example, cytokines play an important role in the recruitment of immune cells to the site of trauma, and can function in stimulating these cells to release opioid peptides, ${ }^{29,30}$ and nerve growth factor alpha can bind directly to receptors on nociceptors to elicit a direct effect. ${ }^{1,3}$ Using our in vitro culture 

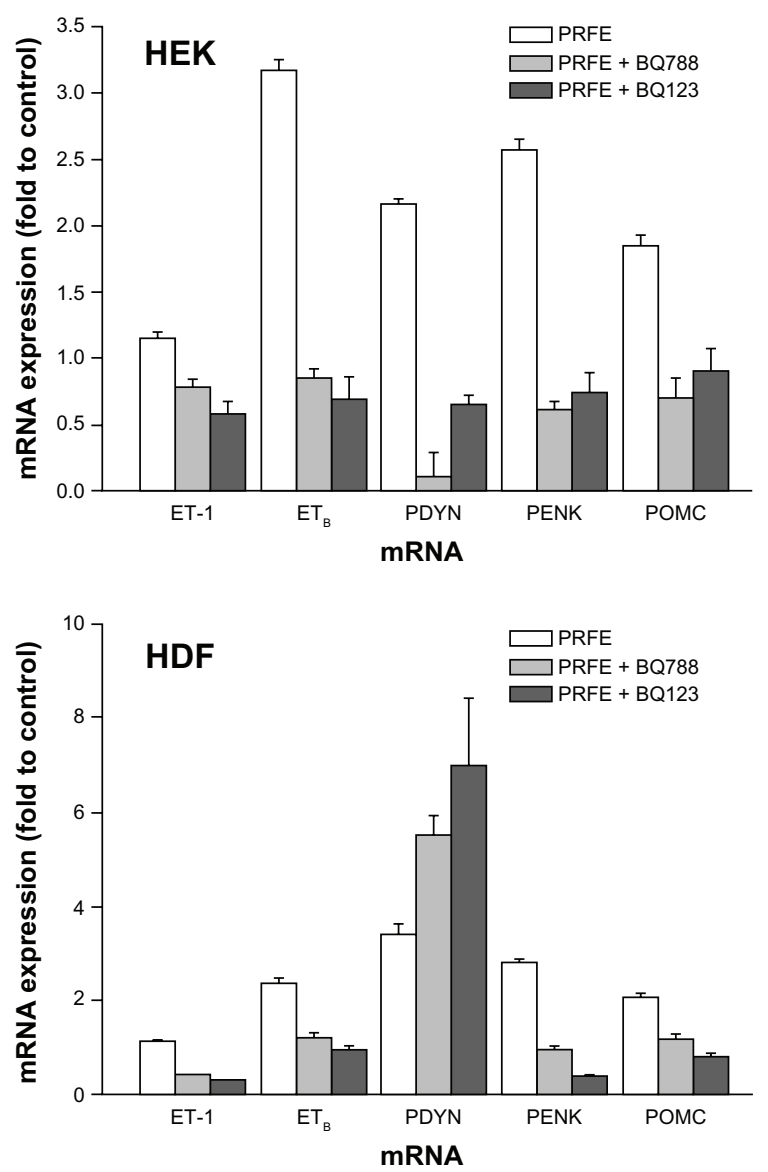

Figure 6 Antagonists of $\mathrm{ET}_{\mathrm{A}}$ and $\mathrm{ET}_{\mathrm{B}}$ receptors inhibit opioid expression after PRFE treatment of HEK and HDF.

Notes: HEK and HDF were pretreated with $\mathrm{ET}_{\mathrm{A}}$ and $\mathrm{ET}_{\mathrm{B}}$ receptor antagonists (BQ788 and BQ123, respectively) for I hour at $100 \mathrm{nM}$ prior to PRFE treatment. Quantitative RT-PCR was performed for the endogenous opioids on RNA isolated 2 hours after PRFE treatment. Data are expressed as percent of untreated antagonist control $(n=6, P<0.01)$.

Abbreviations: ET, endothelin; HDF, human dermal fibroblasts; HEK, human epidermal keratinocytes; PRFE, pulsed radiofrequency energy; POMC, proopiomelanocortin; PENK, proenkephalin; PDYN, prodynorphin; RT-PCR, reverse transcription polymerase chain reaction.

system, we found that PRFE can impact the endogenous expression of some of these factors as well. IL-1 $\beta$ mRNA levels were lower in both cell types (Figure 4) following PRFE treatment relative to control cells, a finding in agreement with clinical findings in which PRFE therapy used postoperatively was associated with lower levels of IL-1 $\beta$ in wound exudates of PRFE-treated patients relative to control-treated patients as early as 1 hour after treatment was initiated, an observation which coincided with lower reported pain. ${ }^{14}$ PRFE treatment of HEK resulted in a lower level of nerve growth factor alpha and tumor necrosis factor alpha factor alpha mRNA relative to control cells (Figure 4), while there were higher levels of nerve growth factor alpha in PRFE-treated HDF relative to control cells. PRFE treatment was also followed by an increase in IL-5, IL-6, and IL-10 mRNA in both cell types. We found no detectible expression of substance $\mathrm{P}$ in either cell type.

In order to get a sense of the direct effects of PRFE treatment, we evaluated the effect of PRFE in our culture system at relatively early time points (ie, hours) after treatment. While changes in mRNA levels detected could be due either to an upregulation of transcription or greater mRNA stability, an increase in peptide levels measured at 2 hours post-treatment reflects an increase in intracellular opioid precursor protein measured at 2 hours post-treatment is more likely to reflect a positive effect on translation or protein stability, indicating that PRFE can have an effect on multiple steps involved in regulating the opioid pathway. Because the current study was done out of interest to understand the molecular mechanism behind how PRFE mediates analgesia in the clinical setting, it is worthwhile to compare the timing of PRFE-mediated effects observed here relative to findings reported in vivo. In randomized, controlled postoperative studies, a clinically observable benefit (eg, reduced pain scores and/or reduced analgesic consumption) has been reported as early as 1 hour after initiation of PRFE treatment. ${ }^{14}$ In other postoperative pain studies, a statistically significant difference in pain scores reported for PRFE-treated versus sham device-treated control subjects occurred as early as 1-3 days postoperatively, depending on the study, ${ }^{12,13}$ and persisted through to the end of each study (both studies followed patients through postoperative day 7). A rapid response to treatment, as reported by Rohde et al, ${ }^{14}$ implies a mechanism that can, in a short amount of time, act on local nociceptors to promote analgesia (such as promoting increased opioid levels). Later onset of analgesia in other studies, as well as long-lasting analgesic effects, could also involve a mechanism that requires more time before an effect on nociception occurs, such as changes in transcription. In addition to reduced pain scores, each of these studies also reported lower narcotic pill consumption in PRFE-treated patients following surgery relative to sham device-treated control subjects.

We propose a working model in which PRFE treatment leads to an increase in both opioid precursor expression and opioid peptide release by keratinocytes and fibroblasts, an effect, which, in vivo, could mediate local analgesia. Upregulation of opioid precursor mRNA in keratinocytes appears to be dependent on activation of endothelin receptors $\left(\mathrm{ET}_{\mathrm{A}}\right.$ and $\left.\mathrm{ET}_{\mathrm{B}}\right)$, whereas an additional pathway also appears to be necessary for PRFE-mediated opioid precursor expression in fibroblasts. In addition, PRFE modulation of cytokine expression in these cells may lead to an altered cytokine environment at the local site of injury, which could also 
affect analgesia. Based on the finding that mRNA levels of enzymes involved in prostaglandin synthesis are upregulated in fibroblasts following PRFE treatment, it needs to be investigated further whether PRFE-mediated analgesia might also involve lipoxins and/or resolvins.

\section{Conclusion}

Treatment of HDF and HEK in culture with PRFE led to changes in the expression of several endogenous factors, which, in vivo, may participate in modulating peripheral nociception. Notably, PRFE treatment led to an increase in endogenous opioid expression and secretion in both cell types tested. Modulation of the endogenous opioid system in different in vivo models has been reported previously following exposure to certain types of extremely low frequency magnetic fields, ${ }^{31,32}$ as well as following electrical stimulation, such as electroacupuncture ${ }^{33,34}$ and transcutaneous electrical nerve stimulation. ${ }^{35}$ To our knowledge, this is the first report showing a positive effect of PRFE on an endogenous opioid pathway. These findings may provide a new insight into the molecular mechanism underlying PRFE-mediated analgesia reported in the clinical setting.

\section{Acknowledgment}

The authors would like to thank Richard Isenberg for help with preparation of the manuscript.

\section{Disclosure}

JM and LMF are employees of Regenesis Biomedical Inc. NJK is a paid consultant for Regenesis Biomedical Inc. This project was supported by funds from Regenesis Biomedical Inc.

\section{References}

1. Basbaum AI, Bautista DM, Scherrer G, Julius D. Cellular and molecular mechanisms of pain. Cell. 2009;139(2):267-284.

2. Dubin AE, Patapoutian A. Nociceptors: the sensors of the pain pathway. J Clin Invest. 2010;120(11):3760-3772.

3. Julius D, Basbaum AI. Molecular mechanisms of nociception. Nature. 2001;413(6852):203-210.

4. Kehlet H, Jensen TS, Woolf CJ. Persistent postsurgical pain: risk factors and prevention. Lancet. 2006;367(9522):1618-1625.

5. Wu CL, Raja SN. Treatment of acute postoperative pain. Lancet. 2011; 377(9784):2215-2225.

6. Hauser W, Bernardy K, Uceyler N, Sommer C. Treatment of fibromyalgia syndrome with gabapentin and pregabalin - a meta-analysis of randomized controlled trials. Pain. 2009;145(1-2):69-81.

7. Furuyashiki T, Narumiya S. Stress responses: the contribution of prostaglandin E(2) and its receptors. Nat Rev Endocrinol. 2011;7(3): 163-175.

8. Stein C, Lang LJ. Peripheral mechanisms of opioid analgesia. Curr Opin Pharmacol. 2009;9(1):3-8.

9. Suleyman H, Demircan B, Karagoz Y. Anti-inflammatory and side effects of cyclooxygenase inhibitors. Pharmacol Rep. 2007;59(3):247-258.
10. Wells N, Pasero C, McCaffery M. Improving the quality of care through pain assessment and management. In: Hughes RG, editor. Patient Safety and Quality: An Evidence-Based Handbook for Nurses. Rockville, MD: Agency for Healthcare Research and Quality; 2008.

11. Guo L, Kubat NJ, Isenberg RA. Pulsed radio frequency energy (PRFE) use in human medical applications. Electromagn Biol Med. 2011;30(1): $21-45$.

12. Heden P, Pilla AA. Effects of pulsed electromagnetic fields on postoperative pain: a double-blind randomized pilot study in breast augmentation patients. Aesthetic Plast Surg. 2008;32(4):660-666.

13. Rawe IM, Lowenstein A, Barcelo CR, Genecov DG. Control of postoperative pain with a wearable continuously operating pulsed radiofrequency energy device: a preliminary study. Aesthetic Plast Surg. 2012;36(2):458-463.

14. Rohde C, Chiang A, Adipoju O, et al. Effects of pulsed electromagnetic fields on interleukin-1beta and postoperative pain: a double-blind, placebo-controlled, pilot study in breast reduction patients. Plast Reconstr Surg. 2010;125(6):1620-1627.

15. Guo L, Kubat NJ, Nelson TR, Isenberg RA. Meta-analysis of clinical efficacy of pulsed radio frequency energy treatment. Ann Surg. 2012; 255(3):457-467.

16. Moffett J, Griffin NE, Ritz MC, George FR. Pulsed radio frequency energy field treatment of cells in culture results in increased expression of genes involved in the inflammation phase of lower extremity diabetic wound healing. J Diabetic Foot Complications. 2010;2(3):57-64.

17. Moffett J, Kubat NJ, Griffin NE, et al. Pulsed radio frequency energy field treatment of cells in culture results in increased expression of genes involved in angiogenesis and tissue remodeling during wound healing. J Diabetic Foot Complications. 2011;3(2):30-39.

18. Boyce ST, Ham RG. Calcium-regulated differentiation of normal human epidermal keratinocytes in chemically defined clonal culture and serumfree serial culture. J Invest Dermatol. 1983;81(Suppl 1):33s-40s.

19. Livak KJ, Schmittgen TD. Analysis of relative gene expression data using real-time quantitative PCR and the 2(-delta delta $\mathrm{C}(\mathrm{T})$ ) method. Methods. 2001;25(4):402-408.

20. Khodorova A, Navarro B, Jouaville LS, et al. Endothelin-B receptor activation triggers an endogenous analgesic cascade at sites of peripheral injury. Nat Med. 2003;9(8):1055-1061.

21. Khodorova A, Zou S, Ren K, et al. Dual roles for endothelin-B receptors in modulating adjuvant-induced inflammatory hyperalgesia in rats. Open Pain J. 2009;2:30-40.

22. Apfelbaum JL, Chen C, Mehta SS, Gan TJ. Postoperative pain experience: results from a national survey suggest postoperative pain continues to be undermanaged. Anesth Analg. 2003;97(2):534-540.

23. Marionnet C, Pierrard C, Lejeune F, et al. Different oxidative stress response in keratinocytes and fibroblasts of reconstructed skin exposed to non extreme daily-ultraviolet radiation. PLoS One. 2010;5(8): e12059.

24. Kristensen MS, Paludan K, Larsen CG, et al. Quantitative determination of IL-1 alpha-induced IL-8 mRNA levels in cultured human keratinocytes, dermal fibroblasts, endothelial cells, and monocytes. J Invest Dermatol. 1991;97(3):506-510.

25. Stein C, Clark JD, Oh U, et al. Peripheral mechanisms of pain and analgesia. Brain Res Rev. 2009;60(1):90-113.

26. Serhan CN, Chiang N, Van Dyke TE. Resolving inflammation: dual anti-inflammatory and pro-resolution lipid mediators. Nat Rev Immunol. 2008;8(5):349-361.

27. Serhan CN, Yacoubian S, Yang R. Anti-inflammatory and proresolving lipid mediators. Annu Rev Pathol. 2008;3:279-312.

28. Xu ZZ, Zhang L, Liu T, et al. Resolvins RvE1 and RvD1 attenuate inflammatory pain via central and peripheral actions. Nat Med. 2010;16(5):592-597.

29. Gao YJ, Ji RR. Chemokines, neuronal-glial interactions, and central processing of neuropathic pain. Pharmacol Ther. 2010;126(1):56-68.

30. Ren K, Dubner R. Interactions between the immune and nervous systems in pain. Nat Med. 2010;16(11):1267-1276. 
31. Kavaliers M, Ossenkopp KP, Tysdale DM. Evidence for the involvement of protein kinase $\mathrm{C}$ in the modulation of morphine-induced 'analgesia' and the inhibitory effects of exposure to $60-\mathrm{Hz}$ magnetic fields in the snail, Cepaea nemoralis. Brain Res. 1991;554(1-2):65-71.

32. Prato FS, Carson JJ, Ossenkopp KP, Kavaliers M. Possible mechanisms by which extremely low frequency magnetic fields affect opioid function. FASEB J. 1995;9(9):807-814.
33. Li P, Longhurst JC. Neural mechanism of electroacupuncture's hypotensive effects. Auton Neurosci. 2010;157(1-2):24-30.

34. [No authors listed]. How does acupuncture work? $\mathrm{Br}$ Med J (Clin Res Ed). 1981;283(6294):746-748.

35. Sluka KA, Deacon M, Stibal A, et al. Spinal blockade of opioid receptors prevents the analgesia produced by TENS in arthritic rats. J Pharmacol Exp Ther. 1999;289(2):840-846.

\section{Publish your work in this journal}

The Journal of Pain Research is an international, peer-reviewed, open access, online journal that welcomes laboratory and clinical findings in the fields of pain research and the prevention and management of pain. Original research, reviews, symposium reports, hypothesis formation and commentaries are all considered for publication.

\section{Dovepress}

The manuscript management system is completely online and includes a very quick and fair peer-review system, which is all easy to use. Visit http://www.dovepress.com/testimonials.php to read real quotes from published authors. 